\title{
Peningkatan Pemahaman Zahir Accounting Bagi Guru Dan Siswa Sekolah Menengah Kejuruan (SMK) Nurul Falah Pekanbaru
}

\author{
DINI ONASIS ${ }^{1}$; IKA BERTY APRILIYANI ${ }^{2}$ \\ Universitas Lancang Kuning \\ Jln. Yos Sudarso KM 08 Rumbai Telp. (0761) 52581 \\ E-mail : onasisdini@gmail.com
}

\begin{abstract}
Activities devotion was conducted in the vicinity of the school vocational (SMK) nurul falah the city of pekanbaru.The participants consists of the students of vocational high school (SMK) nurul falah still have not understand how penggunan accountancy softwares to do bookkeeping or financial reporting. Computer application accounting as one of the to ease presentation of financial report. With the condition of the problems vocational high school (SMK) nurul falah the city of pekanbaru. Devotion can be increase is presentation of faster, financial report precisely and accurately, to ease in understanding and presentation of in financial reporting in accordance with and that which while imposed by (SMK) nurul falah pekanbaru.Through improving the use of software accounting skill computer application heard accounting in improve the ability, presentation of financial report expected students motivated to studies and understand the use of computer application software accounting in supporting students on the performance they are, then find it difficult if should use accounting in the business software. A method of execution for the activities of its service is through socialization how to make the financial report in accordance with the application of accounting standards in accordance with generally accepted accounting software with using computer application for students (SMK) nurul falah pekanbaru to be taken as many as more or less 25 Students. The results of the devotion to the people has been done in the broad includes several components, the success of the target amount of the participants, the planned ketercapaian material, the purpose of training and ability ketercapaian mastery of the material ketercapaian participants in the number of participants can be seen from the number of participants who targeted is 30 people and in fact the 25 people attended by students of participants had almost so that the target could be happy all the participants can take the whole process a simulation of the start to the finish, 100 activities designed \% implemented, and the presence of readiness team $\% 100$ participants
\end{abstract}

Keywords: Accounting, Computer Application Accounting Course

Semakin berkembangnya teknologi dalam dunia industri saat ini menyebabkan sebuah instansi dituntut untuk menggunakan teknologi sebagai penujang utama dari perkejaan instansi tersebut. sistem informasi akuntansi merupakan salah satu bidang teknologi informasi (TI) yang didukung dengan kemampuan dan penguasaan dalam bidang Akuntansi. Pembuatan laporan keuangan disuatu perusahaan merupakan suatu hal yang sangat penting dilakukan, Aplikasi Komputer Akuntansi adalah aplikasi yang menggunakan teknologi informasi yang berbasis Aplikasi Komputer Akuntansi yang bertugas mendapatkan laporan keuangan secara otomatis, cepat dan memiliki tingkat akurasi yang lebih baik dibandingkan secara manual. Mempunyai kemampuan untuk menampilkan data secara cepat, mudah dan efisien. Mempunyai sistem pengamanan berupa password, dapat menyajikan laporan keuangan komparasi sesuai dengan data pada periode yang diinginkan.

Beberapa jenis aplikasi akuntansi komputer yang telah banyak dipakai di seluruh penjuru dunia adalah MYOB, Zahir Accounting, Bee Accounting, Accurate, Payroll, DacEasy, Simply Accounting, General Ledger, Acc Pac, Peachtree, dll. Manfaat aplikasi akuntansi komputer adalah menghasilkan kemudahan untuk menyusun laporan 
keuangan perusahaan dengan akurat, efisien dan cepat. Keuntungan dalam penggunaan aplikasi komputer adalah kecepatan dalam mendapatkan laporan keuangan, yang seringkali dilakukan secara otomatis oleh komputer bila dibandingkan dengan cara manual. Penggunaan komputer juga memiliki tingkat ketepatan tinggi. Aplikasi komputer akuntansi juga mampu menghasilkan dan menampilkan data dengan mudah dan cepat

SMK Nurul Falah yang berlokasi di Jalan Senapelan Kota Pekanbaru merupakan salah satu SMK yang ada di kota Pekanbaru. Dalam mempelajari akuntansi, selain siswa menguasai pengelolaan data akuntansi secara manual juga harus mengetahui sistem akuntansi dengan komputer. Sesuai dengan perkembangan teknologi, penggunaan komputer sudah merupakan hal umum dalam pengolahan data akuntansi agar lebih cepat, tepat dan akurat. Penggunaan komputer untuk mendukung dalam bidang akuntansi merupakan kebutuhan yang harus dipenuhi untuk bekal bagi siswa lulusan program Akuntansi. Hal ini penting untuk menciptakan tenaga profesional dalam bidang akuntansi sesuai dengan kebutuhan dunia kerja sehingga mampu meminimalisir angka pengangguran intelektual di Indonesia.

Salah satu upaya untuk meningkatkan akuntabilitas, pengendalian internal dan keamanan organisasi adalah dengan mengurangi adanya ketidak pahaman yang melaksanakan pencatatan dan membatasi kesalahan pencatatan menggunakan sistem pencatatan yang terkomputerisasi. Untuk itu kegiatan ini bertujuan untuk memberikan pemahaman bagi siswa agar dapat mengimplementasikan sistem pencatatan akuntansi yang terkomputerisasi dengan basis program Aplikasi Komputer Akuntansi.

Permasalahan potensial yang dihadapi mitra adalah : Belum adanya pelatihan dan sosialisasi penerapan sistem pencatatan yang terkomputerisasi zahir
Accounting bagi siswa SMK Nurul Falah mengenai aplikasi komputer akuntansi; Aplikasi komputer akuntansi zahir Accounting yang digunakan dan diterapkan pada SMK Nurul Falah belum optimal, sehingga penggunaan aplikasi komputer akuntansi masih sesuatu hal yang jarang diaplikasikan oleh siswa SMK Nurul Falah; Siswa SMK Nurul Falah merasa kesulitan jika harus menggunakan sistem pencatatan yang terkomputerisasi. Hal ini dikarenakan tidak adanya pedoman atau buku yang dapat dijadikan referensi; Pendidik yang berada disekolah kejuruan kurang memiliki sumber daya manusia yang paham dan mengerti mengenai penerapan sistem pencatatan yang terkomputerisasi yaitu dengan aplikasi komputer akuntansi apapun; Pihak SMK Nurul Falah kurang mengetahui bagaimana untuk mendatangkan para praktisi untuk memberikan pelatihan dan sosialisasi mengenai aplikasi komputer akuntansi

Terkait permasalahan mitra dibutuhkan solusi dalam bagaimana meningkatkan kemampuan dalam penggunaan aplikasi komputer akuntansi sebagai berikut : Diharapkan dapat memberi bekal kepada Guru dan Siswa SMK Nurul Falah sehingga dapat meningkatkan pengetahuan dan pemahaman mengenai penggunaan aplikasi komputer akuntansi; Penggunaan aplikasi komputer akuntansi dengan mudah dan cepat akan memberikan manfaat bagi mereka dalam hal penggunaan aplikasi komputer akuntansi zahir Accounting; Penyajian pelatihan penggunaan aplikasi komputer akuntansi yang mendasarkan pada keadaan yang sebenarnya di dalam perusahaan dan penggunaan pendekatan yang tepat akan menjadikan Siswa SMK Nurul Falah memahami penggunaan aplikasi komputer akuntansi secara mudah dan cepat.

Berdasarkan uraian di atas, untuk meningkatkan cara pembuatan pelaporan keuangan dengan menggunakan software Accounting dengan tingkat pemahaman 
yang masih kecil dan kurangnya pelatihan, maka memeberikan motivasi bagi kami dari dosen Fakultas Ekonomi Universitas Lancang Kuning untuk mengajukan usulan pengabdian kepada masyarakat dengan judul: Peningkatan Pemahaman Zahir Accounting Bagi Siswa-Siswa Sekolah Menengah Kejuruan (SMK) Nurul Falah Kota Pekanbaru

Dengan kondisi permasalahan pada Sekolah Menengah Kejuruan (SMK) Nurul Falah Kota Pekanbaru maka dirumuskan masalah bagaimana Peningkatan Pemahaman Zahir Accounting Bagi SiswaSiswa Sekolah Menengah Kejuruan (SMK) Nurul Falah Kota Pekanbaru

Pengabdian kepada masyarakat ini mempunyai tujuan sebagai berikut : Meningkatkan Pemahaman Zahir Accounting Bagi Siswa-Siswa Sekolah Menengah Kejuruan (SMK) Nurul Falah Kota Pekanbaru; Meningkatkan peran serta Dosen Fakultas Ekonomi Universitas Lancang Kuning dalam ikut serta mensosialisasikan penggunaan software akuntansi yaitu Aplikasi Komputer Akuntansi Zahir Accounting untuk memudahkan dalam memahami pengaplikasian dalam pelaporan keuangan bagi Siswa SMK Nurul Falah

Adapun manfaat dari kegiatan pengabdian kepada masyarakat ini adalah : Memberi pengetahuan kepada siswa-siswa SMK Nurul Falah dan Para Guru mata pelajaran Komputer Akuntansi Zahir Accounting untuk dapat menggunakan Aplikasi Komputer Akuntansi dalam penyajian laporan keuangan; Memberikan pengetahuan kepada siswa-siswa SMK Nurul Falah dan Para Guru mata pelajaran Komputer Akuntansi, untuk dapat menggunakan laporan keuangan sebagai alat untuk memproyeksikan rencana usaha kedepannya sebagai salah satu sarana untuk pengambilan keputusan, sehingga dapat lebih bersaing baik di tingkat nasional maupun di tingkat Masyarakat Ekonomi ASEAN (MEA).

\section{METODE}

Kegiatan Pengabdian Kepada Masyarakat dilakukan kepada satu mitra yaitu Siswa SMK Nurul Falah di Pekanbaru. Dimana peserta yang ikut berpartisipasi dalam kegiatan pengabdian kepada masyarakat sebanyak 25 orang. Dalam rangka mencapai tujuan yang tercantum di atas, maka pelaksanaan kegiatan dilakukan dengan metode yang sistematis dengan langkah-langkah sebagai berikut :

Pelatihan peningkatan pengetahuan tentang definisi dan bentuk dari Laporan Keuangan.

Kegiatan pelatihan yang dilakukan pengusul kepada mitra pengabdian adalah mentransfer informasi tentang definisi laporan keuangan, pentingnya laporan keuangan bagi perusahaan. Materinya yang akan diberikan terdiri dari : Laporan Keuangan; Aplikasi Komputer Akuntansi; Aplikasi Komputer Akuntansi Zahir Accounting

Pelatihan peningkatan pengetahuan tentang jenis perusahaan dilihat dari bidang usaha.

Materinya yang akan diberikan terdiri dari : Perusahaan Jasa, Perusahaan yang bergerak dalam bidang penjualan jasa keahlian. Contoh seperti kantor akuntan publik, usaha salon, usaha bengkel, bank, asuransi, lembaga pendidikan, sekolah, universitas, usaha rental mobil, dan sebagainya. Perusahaan Dagang, Perusahaan yang bergerak dalam bidang membeli dan menjual barang dagangan, seperti penjualan barang dagang. Perusahaan Indusri, Yaitu perusahaan yang mengolah bakan baku menjadi barang jadi dan kemudian menjual hasil produksi. Contohnya seperti usaha mebel, usaha furniture, usaha catering, dan usaha home indutri.

Diskusi. memberikan kesempatan kepada mitra untuk membuat pertanyaan atau diskusi yang diajukan oleh anggota yang berhubungan dengan materi pelatihan bagaimana menyusun laporan keuangan 
dengan aplikasi Aplikasi Komputer Akuntansi Zahir Accounting.

Pelatihan simulasi, yaitu dengan menyelesaikan kasus yang terjadi yang berhubungan dengan penyusunan laporan keuangan dengan Aplikasi Komputer Akuntansi Zahir Accounting. Serta pelatihan diberikan kesempatan untuk mendiskusikan permasalahan yang berkaitan dengan laporan keuangan dengan Aplikasi Komputer Akuntansi yang selama ini dihadapi.

Pendampingan dan evaluasi hasil, kegiatan pendampingan dilakukan untuk memantau peningkatan keterampilan dan kemampuan Mitra dalam penyusunan laporan keuangan dengan Aplikasi Komputer Akuntansi Zahir Accounting Evaluasi hasil dapat diketahui dari perubahan dalam menjawab pertanyaan sebelum dan sesudah kegiatan, kepemahaman peserta dalam menyusun laporan keuangan dengan Aplikasi Komputer Akuntansi Zahir Accounting dan keberhasilan target jumlah peserta pelatihan, ketercapaian target materi yang telah direncanakan, ketercapaian tujuan pelatihan dan kemampuan peserta dalam penguasaan materi. Apabila terdapat kendala, mitra dan Tim Pengabdian kepada masyarakat secara bersama-sama merumuskan permasalahan tersebut dan mencari solusinya.

\section{HASIL}

Pengabdian Kepada Masyarakat ini dilakukan oleh Tim Dosen Fakultas Ekonomi Universitas Lancang Kuning Pekanbaru. Acara bertempat di Ruangan Praktikum Komputer SMK Nurul Falah dengan judul "Peningkatan Pemahaman Zahir Accounting bagi Guru dan Siswa SMk Nurul Falah Pekanbaru". Sebelum kegiatan penyampaian materi mengenai Materi Zahir Accounting tim pengabdian memberikan materi berkenaan siapa saja yang bisa menggunakan zahir accounting dan perusahaan sektor apa saja yang bisa menggunakan zahir accounting sebagai media pencatatan laporan keuangan kemudian, tim dosen memberikan kuesioner untuk mengukur tingkat pemahaman mengenai materi yang akan diberikan pada saat pengabdian ini. Pada kegiatan pembekalan ini peserta sangat antusias mengikuti materi pembekalan terutama untuk materi Zahir Accounting yang diarahkan kepada setiap peserta pengabdian. Jumlah Pertanyaan yang diberikan kepada guru sebanyak 10 pertanyaan adalah sebagai berikut :

Tabel 1. Hasil Rekapitulasi Kuesioner Pengabdian Kepada Masyarakat

\begin{tabular}{|c|c|c|c|}
\hline No & Keterangan & PreTest & PostTest \\
\hline 1 & $\begin{array}{l}\text { Apakah anda mengenal } \\
\text { Aplikasi Pencatatan } \\
\text { Laporan keuangan }\end{array}$ & $10 \%$ & $80 \%$ \\
\hline 2 & $\begin{array}{ll}\text { Apakah } & \text { Anda } \\
\text { mengetahui } & \text { Zahir } \\
\text { Accounting } & \\
\end{array}$ & $10 \%$ & $100 \%$ \\
\hline 3 & $\begin{array}{lr}\text { Apakah semua } & \text { sektor } \\
\text { usahan } & \text { bisa } \\
\text { menggunakan } & \text { zahir } \\
\text { accounting } & \\
\end{array}$ & $10 \%$ & $100 \%$ \\
\hline 4 & $\begin{array}{lr}\text { Apakah } & \text { zahir } \\
\text { accounting } & \text { perlu } \\
\text { menggubah akun dari } & \text { dah } \\
\text { bahasa Inggris } & \text { ke } \\
\text { bahasa Indonseia }\end{array}$ & $0 \%$ & $90 \%$ \\
\hline 5 & $\begin{array}{l}\text { Jumlah modul } \\
\text { perkiraan dalam zahir } \\
\text { accounting ada } 2 \\
\text { modul? }\end{array}$ & $0 \%$ & $90 \%$ \\
\hline 6 & $\begin{array}{lrr}\text { Akun akun } & \text { yang } \\
\text { terdapat } & \text { di } & \text { zahir } \\
\text { accounting } & & \text { bisa } \\
\text { ditambah? } & & \\
\text { disar } & & \end{array}$ & $10 \%$ & $100 \%$ \\
\hline 7 & $\begin{array}{lr}\text { Apakah } & \text { anda } \\
\text { mengetahui } & \text { akun } \\
\text { pembayaran } & \text { piutang } \\
\text { dalam zahir? } & \\
\end{array}$ & $0 \%$ & $80 \%$ \\
\hline 8 & $\begin{array}{lr}\text { Apakah jurnal voucher } \\
\text { digunakan } & \text { untuk } \\
\text { melihat jurnal yang } \\
\text { telah dibuat? }\end{array}$ & $0 \%$ & $80 \%$ \\
\hline 9 & \begin{tabular}{lr}
\multicolumn{2}{l}{ Apakah menurut anda } \\
pencatatan & laporan \\
keuangan & secara \\
komputerisasi & bisa \\
mempermudah & \\
pencatatan? & \\
\end{tabular} & $50 \%$ & $80 \%$ \\
\hline 10 & $\begin{array}{l}\text { Apakah menurut anda } \\
\text { zahir accounting } \\
\text { mempermudah user } \\
\text { dalam mencatat laporan } \\
\text { keuangan }\end{array}$ & $60 \%$ & $100 \%$ \\
\hline
\end{tabular}

Berdasarkan tabel 1 di atas, dapat dilihat bahwa terjadi perubahan yang sangat signifikan dalam menjawab pertanyaan 
sebelum dan sesudah kegiatan pengabdian kepada masyarakat (pre dan post test). Pengetahuan dan pemahaman peserta dalam penggunaan software Zahir Accounting sebelum dilakukan sosialisasi Zahir Accounting sangat rendah dimana rata-rata hanya $10 \%$ yang menjawab mengetahui Zahir Accounting dan terdapat beberapa pertanyaan sebelum dilakukan simulasi hasil yang diperoleh $0 \%$ pertanyaannya berupa pengetahuan dan isi aplikasi zahir accounting. Setelah dilakukan sosialisasi software Zahir Accounting pengetahuan dan pemahaman peserta dalam penggunaan Zahir Accounting meningkat sangat signifikan. Hal ini terlihat bahwa rata-rata hasil jawaban sebesar $80 \%-90 \%$.

\section{PEMBAHASAN}

Hasil kegiatan pengabdian pada masyarakat yang telah dilakukan secara garis besar mencakup beberapa komponen, yaitu keberhasilan target jumlah peserta pelatihan, ketercapaian target materi yang telah direncanakan, ketercapaian tujuan pelatihan dan kemampuan peserta dalam penguasaan materi. Ketercapaian target jumlah peserta dapat dilihat dari jumlah peserta yang ditargetkan adalah 30 orang dan pada kenyataannya kegiatan diikuti sebanyak 25 orang sehingga target jumlah peserta hampir telah dapat terpenuhi. Semua peserta dapat mengikuti seluruh proses simulasi dari awal sampai selesai, kegiatan yang dirancang $100 \%$ terlaksana, dan kehadiran kesiapan tim Peserta $100 \%$. Target penyampaian materi simulasi juga tercapai karena materi dapat disampaikan secara keseluruhan. Dengan demikian maka tujuan kegiatan Pengabdian Kepada Masyarakat dapat terpenuhi.

Pengetahuan dan pemahaman peserta terhadap software Zahir Accounting dievaluasi melalui jawaban post test yang meningkat signifikan dimana 80\%-90\% sudah mengetahui Zahir Accounting dan mengetahui manfaatnya, sebelumnya hanya $10 \%$ yang mengetahui Zahir Accounting Bahkan dengan sosialisasi yang dilakukan dengan cara simulasi satu kasus perusahaan maka terjadi optimisme peserta terhadap kemampuan menggunakan aplikasi software Zahir Accounting dimana 80\% menyatakan bisa menggunakan aplikasi software Zahir Accounting. Hal ini berbanding terbalik dengan jawaban peserta sebelum dilakukan sosialisasi dimana hanya $50 \%$ yang menyatakan bisa menggunakan aplikasi software Zahir Accounting.

Berdasarkan evaluasi pelaksanaan kegiatan dapat diidentifikasi faktor pendukung dalam pelaksanaan program pengabdian kepada masyarakat adalah : Adanya kerjasama yang baik antara tim pengabdian kepada masyarakat dengan peserta siswa-siswa SMK dan Para Guru Mata Pelajaran Komputer Akuntansi SMK Nurul Falah; Adanya kerjasama yang baik antara tim pengabdian kepada masyarakat dengan Kepala Sekolah SMK Nurul Falah beserta jajarannya dalam mensupport terselenggaranya kegiatan ini dalam bentuk pemberian fasilitas ruangan, proyektor, menghadirkan peserta yang akan diberikan sosialisasi Zahir Accounting serta kesediaan Kepala Sekolah SMK Nurul Falah memberikan kata sambutan sekaligus membuka kegiatan pengabdian kepada masyarakat tersebut; Partisipasi aktif dan antusiasme yang tinggi dari peserta siswasiswa SMK dan Para Guru Mata Pelajaran Komputer Akuntansi SMK Nurul Falah dalam mengikuti seluruh rangkaian kegiatan.

\section{SIMPULAN}

Kegiatan pengabdian kepada masyarakat ini dilaksanakan di Kelas SMK Nurul Falah dengan judul "Peningkatan Pemahaman Zahir Accounting bagi Guru dan Siswa SMK Nurul Falah" yang diadakan pada hari Sabtu, 29 Juni 2019 yang dihadiri oleh 25 Peserta, terdiri dari Siswa SMK dan Para Guru Mata Pelajaran Komputer Akuntansi SMK Nurul Falah"

Sesuai dengan tujuan kegiatan pengabdian kepada masyarakat yang telah dilakukan, dapat diambil beberapa kesimpulan sebagai berikut : Meningkatkan peran serta Fakultas Ekonomi Universitas Lancang Kuning 
dalam ikut membantu sekolah sekolah menengah kejuruan yang baru berdiri dengan cara melakukan pembinaan terhadap SMK Nurul Falah melalui kegiatan pengabdian kepada masyarakat dalam bentuk sosialisasi dan peningkatan penggunaan aplikasi software Zahir Accounting untuk pelaporan keuangan bagi Siswa SMK dan Para Guru Mata Pelajaran Komputer Akuntansi SMK Nurul Falah Provinsi Riau berjalan dengan baik dan lancar sesuai dengan yang diharapkan. Siswa SMK dan Para Guru Mata Pelajaran Komputer Akuntansi SMK Nurul Falah telah memiliki pengetahuan dan pemahaman akan pentingnya penggunaan aplikasi software Zahir Accounting dalam pelaporan keuangan yang mudah, cepat dan akurat. Pada pelaksanaan sosialisai, peserta diberikan kuesioner dalam bentuk pre dan post test, hasil dari pre dan post test tersebut menunjukkan perubahan yang sangat signifikan terhadap pengetahuan dan pemahaman peserta terhadap software Zahir Accounting

Berdasarkan kesimpulan di atas, maka dapat kami sarankan hal-hal sebagai berikut: Perlu adanya kegiatan pelatihan penggunaan software Zahir Accounting secara bertahap dan berkelanjutan sebagai lanjutan dari kegiatan sosialisasi ini, agar siswa-siswa SMK Nurul Falah tidak hanya sekedar memiliki pengetahuan dan pemahaman terhadap software Zahir Accounting akan tetapi mereka benar-benar menggunakan software ini dalam membantu pelaporan keuangan dengan mudah, cepat dan akurat. Perlu adanya pendampingan dari instansi terkait.

\section{DAFTAR RUJUKAN}

Ali Imran. 2009. 17 Jurus Mempelajari Aplikasi Komputer Akuntansi , Edisi Kesatu. Yogyakarta: Penerbit Andi

Hendra Wijaya, 2015. Excel Akuntansi, Jakarta : Penerbit PT Elex Media Komputindo

Reeve. 2005. "Accounting : Pengantar Akuntansi". Buku satu. Edisi dua puluh satu. Jakarta; Salemba Empat

Soemarso S. R. 2004. "Akuntansi Suatu Pengantar". Buku satu. Edisi lima. Jakata: Salemba Empat

Tanjung, Yulia, Haryani.2009. Analisis Penerapan PSAK No.1 Tentang Penyajian Laporan Keuangan Pada PT.PLN (Persero) Area Padang. Jurnal Ekonomi dan kewirausahaan.

Yenti,Hidayah.2010. Pelatihan Penyusunan Laporan Keuangan Koperasi bagi kelompok tani wanita "Panen Raya” di Kanagarian Tarok Kecamatan Baso Kabupaten Agam. Artikel Kegiatan Pengabdian Kepada Masyarakat.

Modul :

Inova Fitri Siregar, 2014. Modul Aplikasi Komputer Akuntansi, Edisi Kesatu, Pekanbaru ; Penerbit Pusat Teknologi Informasi dan Pangkalan Data UIN SUSKA Riau. 